\title{
Desenvolvimento de um sistema de pulverização acoplável a pivô central ${ }^{1}$
}

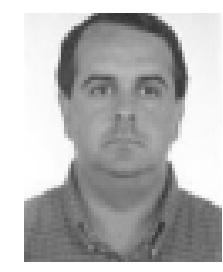

Luis A. A. Vilela², Durval Dourado Neto $^{3}$ \& Tarlei A. Botrel ${ }^{4}$

\author{
1 Parte da tese de Doutorado do primeiro autor, apresentada à Escola Superior de Agricultura "Luiz de Queiroz" \\ 2 Em memória (Foto) \\ ${ }^{3}$ USP/ESALQ. Av. Pádua Dias,11, CEP 13418-900, Piracicaba, SP. E-mail: dourado@esalq..usp.br. Bolsista CNPq \\ ${ }^{4}$ USP/ESALQ. E-mail: tabotrel@esalq.usp.br
}

Protocolo 194 - 19/2/2002 - Aprovado em 7/2/2004

\begin{abstract}
Resumo: Com o objetivo de se aplicar produtos químicos às culturas, desenvolveu-se um sistema de pulverização acoplável a pivô central e também um protótipo do equipamento. Durante a aplicação, a estrutura aérea do pivô central se desloca sem irrigar, apenas transportando o sistema de pulverização sobre a área. O sistema é composto de duas barras de pulverização instaladas em cada vão do pivô. O regime intermitente da pulverização, responsável pela redução da calda aplicada, foi feito por meio de um circuito eletrônico, sincronizado ao acionamento dos motorredutores, que aciona uma válvula solenóide localizada na entrada da barra de pulverização. O sistema desenvolvido possibilita aplicar-se volume de pulverização de até $246 \mathrm{~L} \mathrm{ha-1}$. Os diâmetros de gotas atenderam às recomendações técnicas para aplicação de defensivos agrícolas. Tempos ligado-desligado da válvula solenóide de 0,4 - 2,5, 0,5 - 2,5, 0,3 - 3,5 e 0,4 - 3,5 s resultaram em valores de coeficiente de variação inferiores a $15 \%$, aceitáveis para pulverizações por meio terrestre.
\end{abstract}

Palavras-chave: produto químico, pesticida

\section{Development of a spray system attached to center pivot}

\begin{abstract}
For the application of chemical products a equipment attached to center pivots was developed. During application, the aerial structure of the center pivot system moves, without accomplishing irrigation, just transporting the spray system around the area. In order to compensate different speeds two spray bars were installed in each pivot span. Intermittent spraying was achieved by means of solenoid valves controlled by electronic circuit synchronized with electric motor gears. The system is able to apply a minimum volume of $246 \mathrm{~L} \mathrm{ha}^{-1}$. Drop diameters obtained were compatible with the requirements of application of chemical products. On/off time sequences of $0.4-2.5,0.5-2.5,0.3-3.5$ and $0.4-3.5$ s resulted in coefficients of variation under $15 \%$, that are acceptable for ground based applications.
\end{abstract}

Key words: chemical product, pesticide

\section{INTRODUÇÃO}

Diversos são os tipos de produtos que podem ser aplicados simultaneamente à irrigação (Johnson et al.,1986). Entretanto, alguns trabalhos relatam a dificuldade de aplicação de produtos químicos quando esses devem permanecer na parte aérea da cultura (Silveira et al., 1987; Vieira, 1994; Summer et al., 1997). Segundo Fancelli \& Dourado Neto (2000) no caso específico das técnicas de insetigação, fungigação e herbigação, a eficiência de controle químico, por intermédio de tais produtos, é diretamente proporcional à quantidade de ingrediente ativo que atinge o alvo. Segundo os autores, dentre os diferentes fatores que afetam a quantidade de ingrediente ativo que atinge o alvo, o volume de água por unidade de área é o principal no caso da quimigação foliar. Por este motivo, alguns tipos de formulações químicas não apresentam resultados satisfatórios quando aplicados via água de irrigação, devendo ser distribuídos pela forma tradicional, ou seja, pulverizados.

Diversos autores comentam sobre a possibilidade de se empregar a estrutura aérea de pivôs centrais para aplicação de defensivos agrícolas em áreas irrigadas, caso em que o pivô central se desloca sem realizar irrigação, apenas transportando barras de pulverização (Larsen, 1980; Summer et al., 1997; Dourado Neto \& Fancelli, 1999; Pereira, 2001; Buchleiter, 2001). Nesses equipamentos as gotas são produzidas por 
microaspersores ou bicos pulverizadores utilizados em pulverizadores terrestres. $\mathrm{O}$ volume de pulverização (calda) aplicado por todos esses equipamentos é superior a $2.000 \mathrm{~L}$ $\mathrm{ha}^{-1}$. Este valor é cerca de dez vezes maior que os volumes recomendados para aplicação da maioria dos defensivos agrícolas. Além disso, os autores não informam o tamanho das gotas, que poderiam estar fora dos padrões empregados na pulverização e, se assim fosse, comprometeriam a eficiência do controle químico. O controle da altura da barra de pulverização é possível em alguns modelos, porém dificultada em razão das estruturas de fixação dos acessórios acoplados.

Carvalho (1995) comenta que diâmetro mediano volumétrico (DMV) é o parâmetro mais freqüentemente utilizado para a caracterização do tamanho de gotas nas aplicações de defensivos agrícolas, sendo definido como o diâmetro de gota que divide o volume pulverizado em duas partes iguais. Outro parâmetro utilizado é o diâmetro mediano numérico (DMN) o qual representa o diâmetro que divide o número de gotas produzidas em duas partes numericamente iguais. Segundo Bode (1987) o objetivo de se evitar deriva e obter adequada cobertura do alvo pulverizado, é alcançado utilizando-se gotas com DMV compreendidos entre 100 e $400 \mu \mathrm{m}$.

Matthews (1992) reporta que a uniformidade do espectro de gotas pode ser avaliada por meio do coeficiente de dispersão (r) o qual é obtido pela relação entre os parâmetros DMV e DMN. O espectro de gotas é classificado como homogêneo quando seu valor é inferior a 1,4.

Cupery (1987) cita que a uniformidade de distribuição da pulverização pode ser avaliada por meio do coeficiente de variação (CV). Buchleiter et al.(2001) comentam que valores de CV inferiores a $15 \%$ são adequados para pulverizadores terrestres.

Com este trabalho, objetivou-se desenvolver um sistema de pulverização acoplável a pivô central capaz de aplicar volumes de pulverização recomendados pelos fabricantes de defensivos (inclusive alvo folha) mediante gotas de tamanhos adequados, possibilitando a distribuição uniforme de produtos químicos ou biológicos (contato ou sistêmicos), com controle facilitado de altura da barra aplicadora e movimento sincronizado ao acionamento dos motorredutores, de maneira intermitente.

\section{MATERIAL E MÉTODOS}

\section{Sistema de pulverização}

A metodologia proposta neste trabalho pressupõe a necessidade de instalação de duas barras de pulverização por cada um dos vãos que compõem o pivô central, exceto no primeiro vão, por possuir uma de suas extremidades fixadas à torre central (Figura 1).

O emprego de duas barras de pulverização se justifica pelo motivo de que, ao se analisar o deslocamento de qualquer um dos vãos intermediários que compõem um pivô central, podese identificar quatro diferentes possibilidades de ocorrência de movimento (Figura 2): i) o vão é movimentado por ação do sistema de propulsão instalado na sua torre de sustentação, que se encontra na extremidade mais distante do centro do pivô; ii) o vão é movimentado por ação do sistema de propulsão

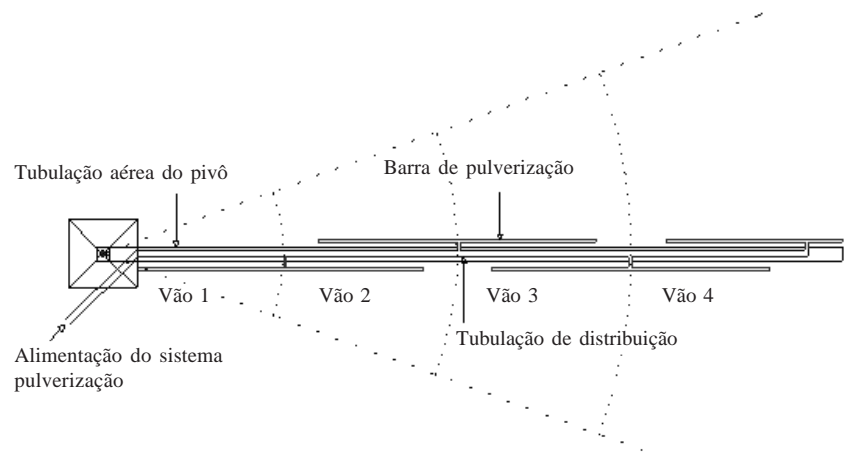

Figura 1. Esquema de posicionamento das barras de pulverização em um pivô central

instalado na sua torre de sustentação, localizada na extremidade mais próxima do centro do pivô; iii) o vão é movimentado por ação de ambos os sistemas de propulsão, e iv) ausência de movimento de todo o vão, pelo fato dos sistemas de propulsão não apresentarem movimento. Essas quatro variantes geram diferentes distribuições de velocidades ao longo do vão. Por exemplo, na primeira possibilidade de movimentação descrita, o ponto do vão que se encontra exatamente sobre a torre de sustentação mais distante do centro do pivô, tem a mesma velocidade desta; os outros pontos apresentam suas velocidades gradualmente reduzidas, desde este primeiro, em que é máxima, até a extremidade oposta do vão, em que não existe movimento; a segunda possibilidade de movimentação pode ser exemplificada exatamente como a primeira, porém o ponto que apresenta velocidade nula se encontrará sobre a torre de sustentação, distante do centro do pivô, o de máxima velocidade, sobre a outra torre de sustentação; enquanto na terceira situação, em razão do acionamento simultâneo dos dois sistemas de propulsão, todos os pontos do vão apresentam exatamente a mesma velocidade; enfim, a quarta e última situação corresponde ao oposto da situação anterior, na qual todos os pontos ao longo do vão possuem velocidade nula.

Os espaçamentos diferenciados entre os emissores que compõem cada uma das barras foram calculados com base na vazão e na largura da faixa molhada pelos mesmos, de maneira

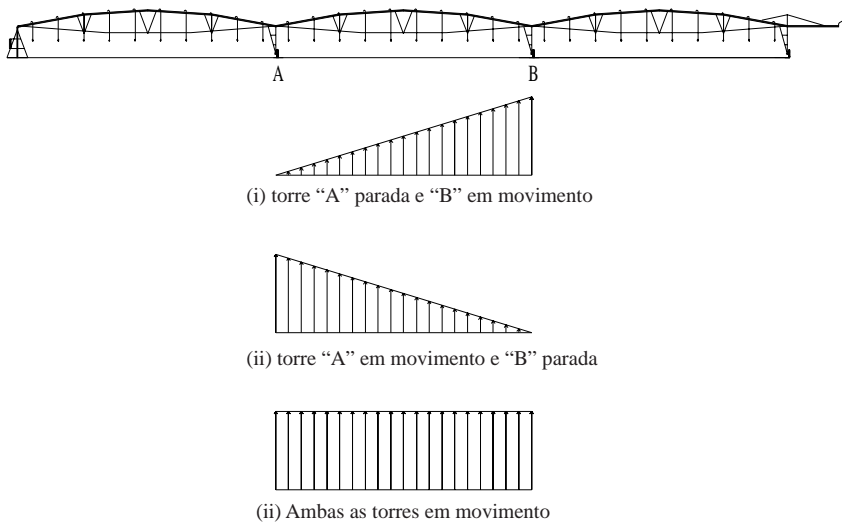

Figura 2. Esquema ilustrativo das variantes de distribuição de velocidades (i, ii, iii) que podem ocorrer ao se analisar um único vão de um pivô central 
que todos os pontos da área pulverizada recebessem o mesmo volume de pulverização. As diferenciações entre os espaçamentos e a escolha do diâmetro do bocal foram determinados objetivando-se compensar as variações de velocidade que podem ocorrer ao longo de cada vão do pivô central (Figura 2).

Durante o acionamento de qualquer um dos motorredutores que promovem o deslocamento do pivô, sinais elétricos são enviados para circuitos eletrônicos que controlam a abertura de válvulas solenóides instaladas no início de cada uma das barras. Esses circuitos são constituídos basicamente de um microcontrolador programável que, associado a outros componentes eletrônicos, possibilita o funcionamento intermitente das barras de pulverização, proporcionando expressiva redução dos volumes de pulverização.

O protótipo do sistema de pulverização desenvolvido neste trabalho foi montado em um pivô central composto por quatro vãos, cada um com 38,9 m de comprimento, instalado na área experimental do Departamento de Engenharia Rural da ESALQ/USP.

As barras de pulverização foram confeccionadas utilizando-se tubos de PVC com diâmetro nominal de $25 \mathrm{~mm}$. O comprimento das barras foi de $30 \mathrm{~m}$ e, na extremidade final, conectou-se um registro, objetivando-se promover a escorva da mesma. A alimentação da barra realizou-se pela extremidade oposta, cuja posição coincide com a torre de sustentação do pivô. Foram utilizados, como elementos formadores de gotas, emissores Fogger 7800 fabricados pela empresa israelense Dan Sprinklers, os quais. podem ser montados com quatro diferentes opções de tamanho de bocal e são comumente empregados como nebulizadores em ambientes protegidos. Válvulas anti-gotas foram incorporadas ao conjunto de emissão com o intuito de manter a barra de pulverização totalmente preenchida com líquido. A pressão de operação dos emissores foi controlada por meio de uma válvula reguladora de pressão $(211 \mathrm{kPa})$ instalada no início de cada barra.

A água usada nos testes foi pressurizada no centro do pivô e conduzida até o início das terceira e quarta torres, por intermédio da tubulação de polietileno de $32 \mathrm{~mm}$. Nesses pontos, onde se encontravam instaladas válvulas reguladoras de pressão, o líquido passou a ser transportado por uma tubulação flexível até as válvulas solenóides. Essas válvulas, posicionadas no início de cada uma das barras de pulverização, tiveram por função controlar, de maneira intermitente e sincronizada ao deslocamento do equipamento de irrigação, o fluxo do líquido para o interior das barras, o que propiciou expressiva redução do volume de pulverização aplicado pelo sistema de pulverização. Os sinais elétricos empregados para abertura das válvulas foram emitidos pelo circuito eletroeletrônico.

As barras de pulverização foram presas a um cabo de aço com diâmetro de $3 \mathrm{~mm}$, disposto entre duas torres de sustentação de um mesmo vão do pivô central. Nas extremidades do cabo foram aplicados esticadores e molas, as quais, por sua vez, foram fixadas ao parafuso central de um sistema móvel provido de rodas (rodízio) que se movimenta no interior de trilhos dispostos verticalmente em cada uma das torres do pivô. Um sistema composto de outros cabos de aço, roldanas e uma catraca, possibilitou a movimentação vertical das barras de pulverização, promovendo o controle de altura das mesmas em relação ao alvo pretendido.

\section{Avaliação do sistema de pulverização}

O tamanho das gotas foi avaliado por meio de papéis sensíveis à água, com dimensões de 26 x $76 \mathrm{~mm}$, dispostos sobre a superfície do solo, formando três linhas (L1, L2 e L3) distanciadas $1 \mathrm{~m}$ entre si e perpendiculares à direção de deslocamento da barra de pulverização. Cada uma das linhas foi composta de 5 cartões distanciados 2,00, 10,72, 19,45, 28,18 e 36,90 m do início do vão, perfazendo o total de 15 pontos de amostragem. Essas distâncias foram obtidas dividindo-se o vão em 5 faixas, mantendo-se uma distância de $2 \mathrm{~m}$ do seu início e final, na tentativa de identificar possíveis influências das torres de sustentação nas quantidades de água recebidas pelos coletores posicionados mais próximos.

Avaliaram-se os papéis sensibilizados pelas gotas por meio do programa computacional específico para esta finalidade que, além de fazer a captura das imagens por meio de varredura ótica, fornece resultados que possibilitam caracterizar o espectro de gotas.

A uniformidade de aplicação foi avaliada através de papéis absorventes de 20 x $20 \mathrm{~cm}$ e gramatura de $80 \mathrm{~g} \mathrm{~m}^{-2}$. A distribuição dos papéis no campo se deu exatamente nas mesmas posições em que foi avaliado o tamanho de gotas. Com o propósito de evitar o contato direto dos papéis com a superfície do solo colocou-se, sob eles, uma superfície plana e não absorvente com dimensões de 25 x $25 \mathrm{~cm}$.

$\mathrm{O}$ volume de pulverização em cada uma das posições foi obtido correlacionando-se o peso de água coletado por cada papel e a sua área. Avaliaram-se os resultados provenientes das combinações de tempos ligados de $0,3,0,4$ e $0,5 \mathrm{~s}$ e desligados de 2,5, 3,0 e 3,5 s.

\section{RESULTADOS E DISCUSSÃO}

\section{Tamanho de gotas}

Na Tabela 1 são apresentados os resultados obtidos no cálculo do DMV e DMN em cada uma das posições avaliadas ao longo do vão do pivô.

Considerando-se os resultados obtidos em todas as posições avaliadas, verifica-se que o DMV está compreendido entre 108,82 e 154,72 $\mu \mathrm{m}$, sendo seu valor médio de $126,30 \mu \mathrm{m}$ (Tabela 1).

Segundo a classificação proposta por Ozeki \& Kunz (s.d.) essas gotas se classificariam como "gotas finas" e, desta forma, conforme Bode (1987) se enquadrariam na faixa recomendada para aplicação de defensivos agrícolas. Esses resultados, de acordo com Matthews (1992) acompanham a tendência atual de aplicações com volumes reduzidos e diâmetros menores, mas como em qualquer tipo de pulverização, restrições à aplicação devem ser impostas para que sua qualidade não venha a ser comprometida em condições de ventos fortes $\left(\geq 10 \mathrm{~km} \mathrm{~h}^{-1}\right)$ e/ou baixa umidade relativa do ar $(\leq 50 \%)$.

De acordo com os resultados apresentados na Tabela 1 , os valores mínimo, médio e máximo de DMN, foram de 89,00, 98,25 e $108,82 \mu \mathrm{m}$, respectivamente. 
Tabela 1. Valores médios de diâmetro mediano volumétrico (DMV) e diâmetro mediano numérico (DMN) observados nas três linhas de avaliação (L1, L2 e L3) em diferentes distâncias (D) do início do vão

\begin{tabular}{|c|c|c|c|c|c|c|c|}
\hline \multicolumn{4}{|c|}{$\operatorname{DMV}(\mu \mathrm{m})$} & \multicolumn{4}{|c|}{$\mathrm{DMN}(\mu \mathrm{m})$} \\
\hline L1 & L 2 & L3 & Média & L1 & L 2 & L3 & Média \\
\hline 108,82 & 154,72 & 127,81 & 130,45 & 88,99 & 108,82 & 88,99 & 95,60 \\
\hline 146,00 & 108,82 & 127,81 & 127,54 & 88,99 & 88,99 & 108,82 & 95,60 \\
\hline 108,82 & 146,00 & 127,81 & 127,54 & 88,99 & 108,82 & 108,82 & 102,21 \\
\hline 127,81 & 127,81 & 127,81 & 127,81 & 108,82 & 108,82 & 88,99 & 102,21 \\
\hline 136,90 & 108,82 & 108,82 & 118,18 & 108,82 & 88,99 & 88,99 & 95,60 \\
\hline \multicolumn{2}{|c|}{ Média geral } & & 126,30 & & & & 98,25 \\
\hline
\end{tabular}

Na mesma tabela verifica-se que tanto os resultados de DMV como de DMN, apresentam coincidência para determinadas posições avaliadas; este fato está relacionado, provavelmente, à metodologia de cálculo utilizada no software E-Sprinkle, cujos diâmetros se enquadrariam dentro de classes de tamanhos preestabelecidos.

O coeficiente de dispersão do espectro de gotas produzidos pelas duas barras de pulverização, calculado com base nos valores médios gerais de DMV e DMN, foi de 1,29. Por ser inferior a 1,4, de acordo com Johnstone, citado por Matuo (1990), o espectro de gotas é classificado como homogêneo, enquadrando-se na classificação CDA (Controlled drop application), condição raramente observada em pulverizadores convencionais.

\section{Uniformidade de aplicação}

Nas Figuras 3A, B e C apresentam-se os resultados dos volumes de pulverização obtidos por meio de papel absorvente, determinados mediante as diferentes combinações de tempos ligados e desligados a que o sistema de pulverização foi submetido. Percebe-se, nesses resultados, que a relação entre os tempos ligado e desligado influencia diretamente o volume de pulverização aplicado.

Embora existam diferenças nos resultados observados em cada um dos pontos e também nas repetições, a redução dos volumes de pulverização, decorrente da intermitência do sistema, possibilitou a aplicação de volumes que variaram de 246 a $543 \mathrm{~L} \mathrm{ha}^{-1}$. Com a programação de outras relações de tempos ligado/desligado pode-se conseguir caldas superiores e inferiores às estabelecidas neste trabalho; entretanto, todos os outros possíveis valores devem ser, obviamente, submetidos a novos ensaios para prévia avaliação da uniformidade de distribuição.

$\mathrm{Na}$ Tabela 2 encontram-se resumidas as caldas estimadas e as observadas para as diferentes relações de tempo programadas no circuito eletro-eletrônico que gerencia o equipamento e, também, descritas as diferenças percentuais entre as lâminas estimadas e as observadas, sendo a primeira considerada a que realmente deveria ser aplicada pelo sistema, além de sumarizados os valores médios de CV determinados em cada um dos testes. Os valores das caldas estimadas foram determinados considerando-se a posição do primeiro emissor (mais distante do ponto de alimentação da barra), a largura da faixa molhada por este e os tempos ligado/desligado programados no dispositivo eletrônico responsáveis pela intermitência de aplicação.
A.

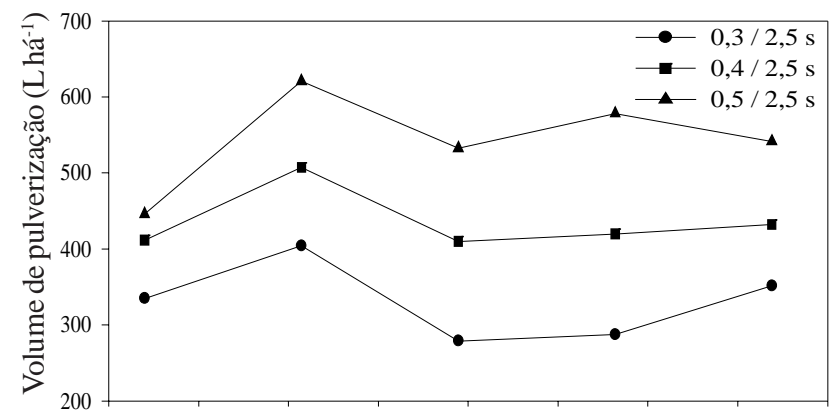

B.

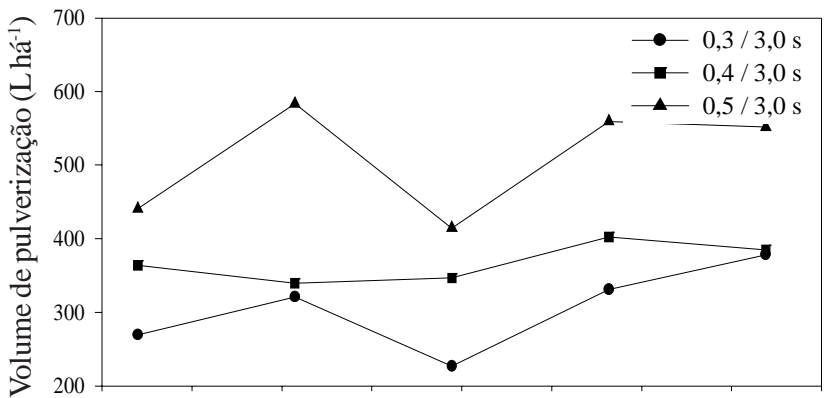

C.

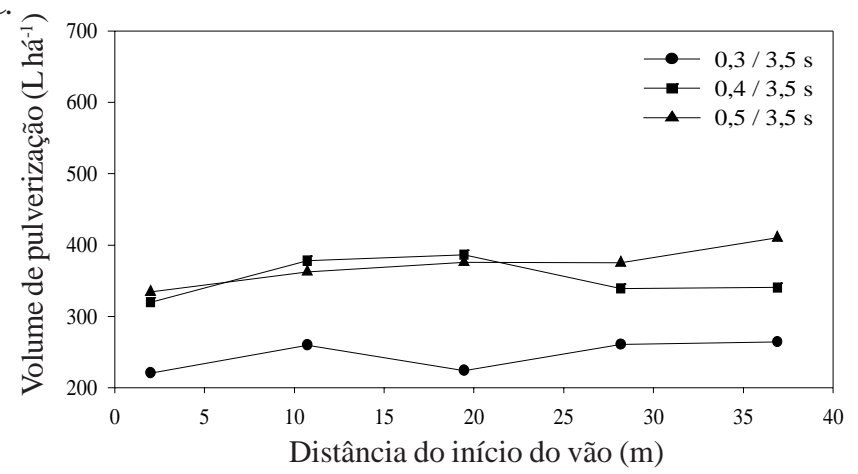

Figura 3. Volumes de pulverização médios aplicados ao longo do vão do pivô central para os tempos ligados e desligados de A: 0,3 - 2,5, 0,4 - 2,5 e 0,5 - 2,5 s de B: 0,3 - 3, 0, 0,4 - 3, 0 e 0,5 $-3,0$ s e C: $0,3-3,5,0,4-3,5$ e $0,5-3,5$ s

Pelos resultados apresentados, verifica-se que as lâminas observadas foram inferiores às estimadas, cujas variações podem ser explicadas, possivelmente, por diversas causas, tais como o tempo de resposta hidráulica diferenciado em cada pulso, erro metodológico de coleta e amostragem possíveis evaporações decorridas após a exposição dos coletores à pulverização, dentre outras. 
Tabela 2. Diferenças percentuais (Dp) entre as lâminas estimadas e as observadas e o coeficiente de variação $(\mathrm{CV})$ determinados para cada relação de tempos ligado/desligado avaliadas

\begin{tabular}{cccccccc}
\hline \multicolumn{2}{c}{ Tempo - s } & & \multicolumn{2}{c}{ Calda $\left(\mathrm{L} \mathrm{ha}^{-1}\right)$} & Dp & CV \\
\cline { 1 - 2 } Ligado & Desligado & & Estimada & Observada & $(\%)$ & $(\%)$ \\
\hline 0,3 & 2,5 & & 389,11 & 331,5 & 14,8 & 16,3 \\
0,4 & 2,5 & & 500,93 & 436,1 & 12,9 & 12,7 \\
0,5 & 2,5 & & 605,29 & 543,8 & 10,2 & 12,6 \\
0,3 & 3,0 & & 330,16 & 305,2 & 7,6 & 20,0 \\
0,4 & 3,0 & & 427,26 & 367,5 & 14,0 & 22,6 \\
0,5 & 3,0 & & 518,82 & 509,8 & 1,7 & 15,3 \\
0,3 & 3,5 & & 286,71 & 246,0 & 14,2 & 13,0 \\
0,4 & 3,5 & & 372,48 & 353,0 & 5,2 & 13,9 \\
0,5 & 3,5 & & 453,97 & 371,5 & 18,2 & 16,7 \\
\hline
\end{tabular}

Embora todo o sistema tenha sido projetado para realizar aplicações com valores de CV próximos a 8,6\% verifica-se, na Tabela 2, que as análises provenientes dos ensaios de uniformidade de distribuição resultaram em CV entre 12,6 e $22,6 \%$. Para os tempos ligado/desligado de 0,4-2,5, 0,5-2,5, 0,33,5 e $0,4-3,5$ s obtiveram-se valores de CV inferiores a $15 \%$, sendo estes, de acordo com os relatos de Buchleiter et al.(2001), considerados adequados para aplicações por meio de equipamentos terrestres; já para os demais tempos, obtiveramse valores de CV superiores a $15 \%$, os quais, de acordo com Cupery (1987) resultam em aplicações de qualidade marginal. A metodologia empregada nas análises de uniformidade foi idealizada neste trabalho e, embora tenha sido aplicada criteriosamente, pode ter influenciado nos resultados obtidos.

\section{CONCLUSÃO}

O equipamento desenvolvido é capaz de aplicar, de maneira uniforme, volumes de pulverização recomendados para a maioria das formulações de defensivos agrícolas, com gotas de tamanho adequado possibilitando, inclusive, distribuir produtos cujo alvo é a parte aérea da planta (contato ou sistêmico).

\section{LITERATURA CITADA}

Bode, L.C. Spray application technology. In: Whorter, C.G.M.; Gebhardt, M.R. (eds.). Methods of applying herbicides. West Clark: WSSA, 1987. cap.6, p.85-110.
Buchleiter, G.; Farahani, H.J.; Bartlett, G. Evaluation of lowvolume chemical application system. In: Annual International ASAE Meeting, 2001, Sacramento. Abstracts. St. Joseph: ASAE, 2001. p.535-542. ASAE Paper, 012164

Carvalho, W.P.A. Estudo comparativo entre métodos de amostragens de gotas para determinação de faixa de deposição nas aplicações de produtos líquidos. Botucatu: Faculdade de Ciências Agronômicas, Universidade Estadual Paulista "Júlio de Mesquita Filho", 1995. 64p. Dissertação Mestrado

Cupery, E.W. Application accuracy. In: Whorter, C.G.M; Gebhardt, M.R.(eds.). Methods of applying herbicides. West Clark: WSSA, 1987. cap.5, p.63-84.

Dourado Neto, D.; Fancelli, A.L. Quimigação na cultura do feijão. In: Folegatti, M.V. (ed.). Fertirrigação. Guaíba: Agropecuária, 1999. p.393-432.

Fancelli, A.L.; Dourado Neto, D. Produção de milho. Guaíba: Agropecuária, 2000. 360p.

Johnson, AW.; Young, J.R.; Threadgill, E.D.; Dowler, C.C.; Summer, D.R. Chemigation for crop production management. Plant Disease, v.70, n.11, p.11-15, 1986.

Larsen, R. Piggyback system turns pivot into chemical applicator. Irrigation Age, v.15, n.3, p. 8-9, 1980.

Matthews, G.A. Pesticide applications methods. Singapore: Longman, 1992.405p.

Matuo, T. Técnicas de aplicação de defensivos agrícolas. Jaboticabal: FUNEP, 1990. 139p.

Ozeki, Y.; Kunz, R.P. Manual de aplicação aérea. São Paulo: Ciba Agro, s.d. 46p.

Pereira, A.S. Desenvolvimento de um protótipo aplicador de produtos químicos para um sistema de irrigação pivô central. Piracicaba: ESALQ, 2001.64p. Tese Doutorado

Silveira, R.C.M.; Hills, D.J.; Yates, W.E. Insecticide oil distribution pattern from a linear move spray head. Transactions of the ASAE, St. Joseph, v.30,n.2, p.438-441, 1987.

Summer, H.R.; Garvey, P.M.; Heermann, D.F.; Chandler, L.D. Center pivot irrigation attached sprayer. Applied Engineering in Agriculture, St. Joseph, v.13, n.3, p.323-327, 1997.

Vieira, R.F. Introdução à quimigação. In: Costa, E.F.; Vieira, R.F.; Viana, P.A. (eds.). Aplicação de produtos químicos e biológicos via água de irrigação. Brasília: EMBRAPA, SPI, 1994. cap.1, p.13-40. 